\title{
Major quantitative trait loci influencing milk production and conformation traits in Guernsey dairy cattle detected on Bos taurus autosome 19
}

\author{
B. Li, ${ }^{1}$ P. M. VanRaden, ${ }^{1} \odot$ D. J. Null, ${ }^{1}$ J. R. O’Connell, ${ }^{2}$ and J. B. Cole ${ }^{1 *} \odot$ \\ ${ }^{1}$ Animal Genomics and Improvement Laboratory, Henry A. Wallace Beltsville Agricultural Research Center, USDA Agricultural Research Service, \\ Beltsville, MD 20705-2350 \\ ${ }^{2}$ School of Medicine, University of Maryland, Baltimore 21201
}

\section{ABSTRACT}

The goal of this study was to identify potential quantitative trait loci (QTL) for 27 production, fitness, and conformation traits of Guernsey cattle through genome-wide association (GWA) analyses, with extra emphasis on BTA19, where major QTL were observed for several traits. Animals' de-regressed predicted transmitting abilities (PTA) from the December 2018 traditional US evaluation were used as phenotypes. All of the Guernsey cattle included in the QTL analyses were predictor animals in the reference population, ranging from 1,077 to 1,685 animals for different traits. Single-trait GWA analyses were carried out by a mixed-model approach for all 27 traits using imputed high-density genotypes. A major QTL was detected on BTA19, influencing several milk production traits, conformation traits, and livability of Guernsey cattle, and the most significant SNP lie in the region of 26.2 to $28.3 \mathrm{Mb}$. The myosin heavy chain 10 (MYH10) gene residing within this region was found to be highly associated with milk production and body conformation traits of dairy cattle. After the initial GWA analyses, which suggested that many significant SNP are in linkage with one another, conditional analyses were used for fine mapping. The top significant SNP on BTA19 were fixed as covariables in the model, one at a time, until no more significant SNP were detected on BTA19. After this fine-mapping approach was applied, only 1 significant SNP was detected on BTA19 for most traits, but multiple, independent significant SNP were found for protein yield, dairy form, and stature. In addition, the haplotype that hosts the major QTL on BTA19 was traced to a US Guernsey born in 1954. The haplotype is common in the breed, indicating a long-term influence of this QTL on the US Guernsey population.

Received April 22, 2020.

Accepted September 7, 2020.

*Corresponding author: john.cole@ars.usda.gov
Key words: fine mapping, Guernsey cattle, quantitative trait loci

\section{INTRODUCTION}

Guernsey cattle, originally from the Isle of Guernsey in the English Channel off the coast of France, have been developed over 2 centuries and are renowned for a unique golden-colored milk high in protein and butterfat (World Guernsey Cattle Ferderation, 2004). In the United States, traditional genetic evaluations for Guernsey have been available for decades, and official genomic evaluations for Guernsey started in 2016 (Cooper et al., 2016). Genomic evaluations for Guernsey were initially based on 2,376 genotyped Guernsey bulls and cows from the United States, Canada, the United Kingdom, and the World Guernsey Cattle Federation (Isle of Guernsey; Cooper et al., 2016). A potential QTL on BTA19 influencing several traits [e.g., milk, productive life, SCS, daughter pregnancy rate (DPR), cow conception rate, size, rump, udder, and teat length] was briefly mentioned by Cooper et al. (2016), using a 60,671 SNP panel. However, due to limitations of data size and marker density, the precise location of the QTL is unknown, and it is unclear whether multiple QTL on BTA19 underlie associated traits.

Currently in the United States, the number of genotyped animals for Guernsey evaluation has almost doubled compared with the initial data. Prediction reliabilities for Guernsey evaluation have increased since 2016, and more traits have been analyzed (net merit, 5 yield traits, 7 functional traits, and 14 conformation traits). A new reference assembly of the bovine genome, ARS-UCD 1.2, was applied to official genomic evaluation, and the new map has improved performances in marker locations, sequence alignment, and genotype imputation compared with the previous UMD 3.1 reference assembly (Null et al., 2019). Meanwhile, highdensity (HD) genotypes became available for a larger number of Guernsey animals, making it possible to 
Table 1. Number of animals for each trait included in genome-wide association studies

\begin{tabular}{lrrr}
\hline & \multicolumn{3}{c}{ Number of animals } \\
\cline { 2 - 4 } Trait & Total & \multirow{2}{*}{ Bulls } & Cows \\
\hline Yield traits & & & \\
Net merit & 1,685 & 503 & 1,182 \\
Productive life & 1,377 & 484 & 893 \\
SCS & 1,358 & 483 & 875 \\
Daughter pregnancy rate & 1,355 & 481 & 874 \\
Heifer conception rate & 1,354 & 484 & 870 \\
Cow conception rate & 1,077 & 248 & 829 \\
Livability & 1,305 & 420 & 885 \\
Gestation length & 1,376 & 483 & 893 \\
Final score & 1,503 & 487 & 1,016 \\
Stature, strength, dairy form & 1,495 & 420 & 1,075 \\
Foot angle, rear legs (side view) & 1,546 & 471 & 1,075 \\
Rump angle, front teat placement & 1,535 & 471 & 1,064 \\
Rump width, rear udder height, & 1,549 & 474 & 1,075 \\
udder depth & 1,550 & 474 & 1,076 \\
Teat length, fore udder attachment & 1,552 & 474 & 1,078 \\
Udder cleft & 1,545 & 474 & 1,071 \\
\hline 1Yi tits & &
\end{tabular}

${ }^{1}$ Yield traits include milk yield, fat yield, protein yield, fat percentage, and protein percentage.

obtain imputed HD genotypes for all Guernsey in the national database.

Given larger amounts of information available, the aim of this study was to locate potential QTL for 27 production, fitness, and conformation traits of Guernsey cattle through genome-wide association (GWA) analyses using HD genotypes. Extra emphasis was placed on BTA19, where a major QTL was observed for several traits. A conditional analysis was further carried out to test for multiple QTL on BTA19 for the traits showing major QTL on BTA19.

\section{MATERIALS AND METHODS}

\section{Data}

Twenty-seven traits of Guernsey cattle were studied, including net merit, 5 yield traits, 7 functional traits, and 14 conformation traits (Table 1). Animals' deregressed PTA from the December 2018 traditional evaluation were used as the phenotype for each trait. Although yield deviations and daughter yield deviations may be more accurate than de-regressed PTA, these were not available for all traits for all animals. The animals used in this study include both bulls and cows from the reference population used to compute the US national genomic evaluations (Wiggans et al., 2017), which is defined as those animals with PTA reliability higher than the reliability of their parent average (PA); as a result, the set of animals varies slightly from trait to trait. All animals were genotyped and imputed up to HD genotypes of 643,059 SNP variants. The 643,059 variants were derived from $777 \mathrm{~K}$ Illumina BovineHD Genotyping BeadChip (Illumina Inc., San Diego, CA) and $80 \mathrm{~K}(79,276 \mathrm{SNP})$ markers used in the official US dairy cattle evaluations (VanRaden et al., 2017; Wiggans et al., 2019). Properties of the chips used to genotype the animals in this study and imputation accuracy for each are shown in Table 2. Chromosome locations of the imputed HD markers were from the ARS-UCD 1.2 assembly of the Bos taurus genome (Rosen et al., 2020).

In the data filtering and quality control processes, SNP with call rates $<0.90$, SNP with minor allele frequency $<0.01$, and animals with parent-progeny Mendelian conflicts were omitted from the data set, fol-

Table 2. The SNP count, number of genotyped bulls and cows, and imputation accuracy for the chips used in this study

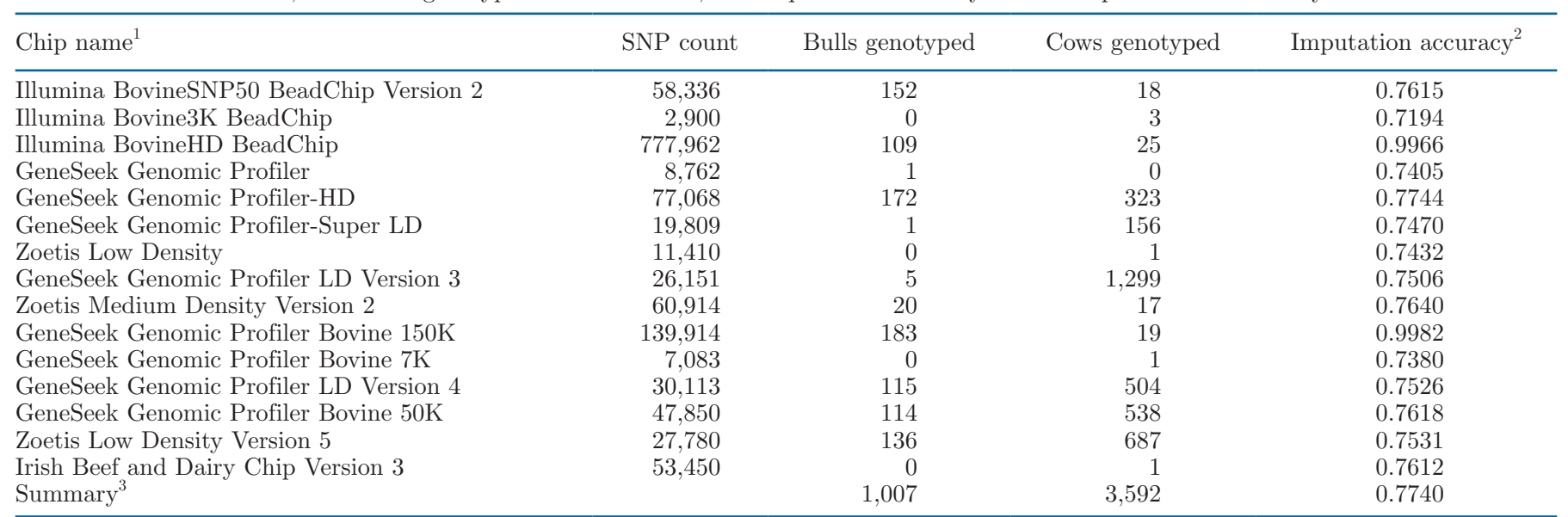

${ }^{1}$ Illumina Inc., San Diego, CA; GeneSeek, Inc., Lincoln, NE; Zoetis, Inc., Parsippany, NJ; Irish Cattle Breeding Association, Bandon, County Cork, Ireland.

${ }^{2}$ Mean imputation accuracy to high density $(\mathrm{n}=643,059 \mathrm{SNP})$, measured as the squared correlations of imputed with true genotypes averaged across loci for each animal.

${ }^{3}$ Total number of bulls and cows genotyped, and the weighted average imputation accuracy over all chips used. 
lowing the method described by Wiggans et al. (2010). After quality control, the number of markers remaining in the final data set for GWA analyses ranged from 574,262 to 579,581 for different traits, and the number of genotyped animals included in the following GWA analyses is shown in Table 1. Mean imputation accuracy, estimated as the squared correlations of imputed with true genotypes averaged across loci for each animal from a series of simulaton studies (VanRaden et al., 2013), was $87.4 \pm 2.3 \%$.

\section{Genome-Wide Association Analyses}

Single-trait GWA analyses were carried out by a mixed-model approach using MMAP version 2019_05_10_13_08.intel (O'Connell, 2020). The genetic model used for GWA analyses was

$$
\mathbf{y}=1 \mu+\mathbf{I s e x}+\mathbf{X b}+\mathbf{g}+\mathbf{e}
$$

where $\mathbf{y}$ is the vector of de-regressed PTA for a single trait, calculated as $\mathbf{y}=P T A / \operatorname{Rel}_{P T A}^{2}$ (Garrick et al., 2009); $\mu$ is the global mean, and $\mathbf{1}$ is a vector of ones; sex is a vector of fixed effects of animal sex, and $\mathbf{I}$ is an identity matrix assigning individuals to their sex, which was found to be statistically significant $(P<0.05)$; $\mathbf{X}$ is a matrix of genotypes (coded as 0,1 , or 2 copies of the minor allele) for the animals with observations in $\mathbf{y}$, and $\mathbf{b}$ is a vector of marker effects; $\mathbf{g}$ is a vector of polygenic effects accounting for population structure with $\operatorname{Var}(\mathbf{g}) \sim N\left(\mathbf{0}, \mathbf{G} \sigma_{g}^{2}\right)$, where the genomic relationship matrix $(\mathbf{G})$ was built using the HD markers and $\sigma_{g}^{2}$ is the genetic variance; and $\mathbf{e}$ is a vector of random residual errors with $\operatorname{Var}(\mathbf{e}) \sim N\left(\mathbf{0}, \mathbf{R} \sigma_{e}^{2}\right)$, where $\sigma_{e}^{2}$ is residual error variance and $\mathbf{R}$ is a diagonal matrix that adjusts $\sigma_{e}^{2}$ to account for the different amount of information available for bulls versus cows.

Preliminary analyses including only bulls, only cows, and bulls and cows together suggested that weighting of the residual variances could reduce stratification and stabilize solutions. The weights included in $\mathbf{R}$ were a function of reliabilities of traditional PTA $\left(\operatorname{Rel}_{P T A}\right)$ and reliabilities of traditional PA $\left(\operatorname{Rel}_{P A}\right)$, as

$$
\text { Weight }_{\text {Animal }}=\frac{\operatorname{Rel}_{\text {Animal }}}{1-\operatorname{Rel}_{\text {Animal }}},
$$

where reliabilties for each animal $\left(R e l_{\text {Animal }}\right)$ were computed as a function of daughter equivalents $(D E)$ :

$$
R e l_{\text {Animal }}=\frac{D E_{P T A}-D E_{P A}}{D E_{P T A}-D E_{P A}+1}
$$

and daughter equivalents for PTA and PA were calculated as

$$
D E_{P T A}=\frac{R e l_{P T A}}{1-\operatorname{Rel}_{P T A}}
$$

and

$$
D E_{P A}=\frac{\operatorname{Rel}_{P A}}{1-\operatorname{Rel}_{P A}} .
$$

Sex was also included in all models, because both bulls and cows were included in each analysis, which resulted in an approximate 3 -fold increase in genotyped animals. Double-counting of information from both parents and their progeny was avoided by using a multiple-stage genomic BLUP mode that includes a 3-component seletion index of PA, genomic information, and a pedigree index based on relationships among genotyped animals (VanRaden et al., 2009). Subtraction of the pedigree index term avoids double-counting of the genomic information also included in the PA. This method may not avoid all double-counting but, in practice, seems to work reasonably well. A Bonferroni correction was applied to account for multiple testing in single-trait GWAS. Genome-wide significance thresholds corresponding to a nominal $5 \%$ type I error were applied and were $0.05 / \mathrm{N}$, where $\mathrm{N}$ was the number of markers. The genome-wide significance threshold ranged from $8.6 \times 10^{-8}$ to $8.7 \times 10^{-8}$ for different traits, due to the different reference population sizes causing slightly different numbers of tested markers.

\section{Conditional Analyses on BTA19}

For the traits that showed major QTL on BTA19 from GWA analyses, conditional analyses were applied to detect independent SNP significantly associated with the traits on BTA19, considering many significant SNP from GWA were in high linkage disequilibrium (LD). In the next round, the most significant SNP on BTA19 observed from previous GWA analyses was fitted as a covariate in model [1], and the remaining SNP were scanned to detect the presence of other genome-wide significant SNP on BTA19. If the result of that round detected any other significant SNP on BTA19, the most significant SNP from that round was fixed as another covariate in the model, and the remaining SNP were 
Table 3. Single nucleotide polymorphisms with large effects on BTA19 in Guernsey cattle: SNP names, positions (Pos), minor allele frequencies (MAF), $P$-values of the SNP effect, closest gene to the top SNP, direction of the SNP effect $\left(+=\right.$ positive, $-=$ negative), ${ }^{1}$ and size of the effect in additive genetic SD

\begin{tabular}{|c|c|c|c|c|c|c|c|c|}
\hline Trait & Pos (bp) & SNP name & $\mathrm{SNP}^{2}(\mathrm{rs})$ & MAF & $P$-value & Gene & Direction & Effect \\
\hline Protein & $27,838,415$ & ARS-BFGL-NGS-95155 & rs110502730 & 0.44 & 2.79E-09 & $A U R K B$ & - & 0.1860 \\
\hline Productive life & $26,298,780$ & BovineHD1900008028 & rs135102299 & 0.42 & $8.26 \mathrm{E}-17$ & $R A B E P 1$ & - & 0.3530 \\
\hline Fat percent ${ }^{3}$ & $27,838,415$ & ARS-BFGL-NGS-95155 & rs110502730 & 0.44 & $2.32 \mathrm{E}-07$ & $A U R K B$ & + & 0.1434 \\
\hline Rump angle & $28,339,070$ & BovineHD1900008517 & rs136174573 & 0.49 & 7.09E-12 & PIK3R6 & + & 0.2112 \\
\hline Rump width & $28,096,864$ & BovineHD1900008425 & rs137768921 & 0.46 & $2.21 \mathrm{E}-17$ & MYH10 & + & 0.1295 \\
\hline Dairy form & $28,099,297$ & BovineHD1900008426 & rs133856141 & 0.46 & $2.82 \mathrm{E}-60$ & MYH10 & + & 0.4683 \\
\hline Teat length & $28,099,297$ & BovineHD1900008426 & rs133856141 & 0.46 & $4.14 \mathrm{E}-15$ & MYH10 & + & 0.1973 \\
\hline Udder depth & $25,859,348$ & BovineHD1900007870 & rs132856966 & 0.48 & $4.60 \mathrm{E}-21$ & $W S C D 1$ & + & 0.3984 \\
\hline Livability $^{3}$ & $26,818,990$ & BovineHD4100014094 & rs109888162 & 0.40 & $2.82 \mathrm{E}-06$ & - & + & 0.2456 \\
\hline Net merit & $35,216,837$ & BovineHD1900010409 & rs136421332 & 0.01 & $1.30 \mathrm{E}-08$ & TMEM11 & - & 0.1696 \\
\hline $\mathrm{SCS}^{3}$ & $36,221,449$ & BovineHD1900010689 & rs41910915 & 0.01 & 1.39E-06 & - & - & 0.1322 \\
\hline $\mathrm{DPR}^{4}$ & $35,283,135$ & Hapmap42945-BTA-45128 & rs41643572 & 0.01 & $9.72 \mathrm{E}-10$ & MAР2КЗ & - & 0.1632 \\
\hline
\end{tabular}

${ }^{1}$ The sign is based on the effect of the minor allele and is relative to the trait definition (e.g., a positive SNP effect for stature is associated with taller cows).

${ }^{2} \mathrm{rs}=$ NCBI RefSeq ID.

${ }^{3}$ The top SNP for protein percentage, fat percentage, livability, and SCS were chromosome-wide significant but not genome-wide significant.

${ }^{4}$ Daughter pregnancy rate.

${ }^{5}$ Heifer conception rate.

scanned in the subsequent round. This same procedure was iterated until no additional SNP were detected as significant on BTA19. The list of significant SNP that were fixed as covariates were collected for each trait as the independent SNP on BTA19 significantly influencing the trait, inferring single or multiple QTL for the trait on BTA19.

\section{Haplotype Analyses for QTL on BTA19}

Based on the GWA results, the haplotype that hosts the major QTL on BTA19 was located using findhap. f90 version 3 (VanRaden, 2016). The frequency of the haplotype in the Guernsey population was detected over years, and the haplotype was traced back to detect the founder animal of this haplotype in the Guernsey population. In addition, the haplotype was also traced back in Holstein, Jersey, Brown Swiss, and Ayrshire populations in the United States, to detect the appearance of this haplotype in other dairy breeds.

\section{RESULTS AND DISCUSSION}

\section{Major QTL Detected on BTA19}

A large QTL was detected on BTA19, influencing several milk production traits, conformation traits, and livability of Guernsey cattle, where the top SNP of the QTL lie in the region of 26.2 to $28.3 \mathrm{Mb}$ on BTA19 (Table 3). We used a mixed-model approach that incorporated reliability variation across individual animals. The average genomic inflation factor of our GWA analyses was 0.92 (ranging from 0.83 to 0.99 ) for all analyzed traits.

The detected QTL on BTA19 in the region of 26.2 to $28.3 \mathrm{Mb}$ has a large effect on milk yield, protein yield, and productive life, with the effects reaching genomewide significance (Figure 1). For fat yield, the effect of the QTL on BTA19 was not shown to be significant, and the largest effects flanked the diacylglycerol Oacyltransferase 1 (DGAT1) gene on BTA14 (Figure 1). For fat percentage and protein percentage, effects of this QTL on BTA19 reached chromosome-wide significance level, but the effect sizes were smaller than the effect of DGAT1 (Figure 2). Meanwhile, the detected QTL at 26.2 to $28.3 \mathrm{Mb}$ on BTA19 had a highly significant effect on several conformation traits, including stature, strength, dairy form, teat length, udder depth, rump angle, and rump width of Guernsey cattle (Figure 3; Table 3). In addition, apart from the candidate QTL region of 26.2 to $28.3 \mathrm{Mb}$ on BTA19 for production and conformation traits, another region at 35.2 to 37.7 $\mathrm{Mb}$ on BTA19 showed significant effects on net merit, DPR, heifer conception rate, and SCS (Figure 4). The top associated SNP in this region had relatively low minor allele frequencies (Table 3). The low heritability of fertility traits and SCS may have contributed to noise in estimating SNP effects for these traits.

Selection over many generations has not resulted in notable allele frequency changes for the QTL, despite 
its large effect on several traits. This is probably because it favorably affects milk and stature but unfavorably affects health and fertility traits (Table 3). Genetic trends were favorable for milk yield and unfavorable for DPR (Figure 5), a pattern similar to the well-known correlation of production gains with fertility reductions in US Holstein cattle (e.g., Lucy, 2001). It is also important to note that the SNP with the largest effect on lifetime net merit is located in a different region $(\sim 35.2 \mathrm{Mbp})$ than the QTL currently being studied, so selection for lifetime net merit would not necessarily be expected to change the frequency of the QTL. The total merit indices designed for commercial dairy farmers in the United States have changed over time (Table 4), with substantial selection emphasis on milk, fat, and protein until 1994. They did not include any emphasis
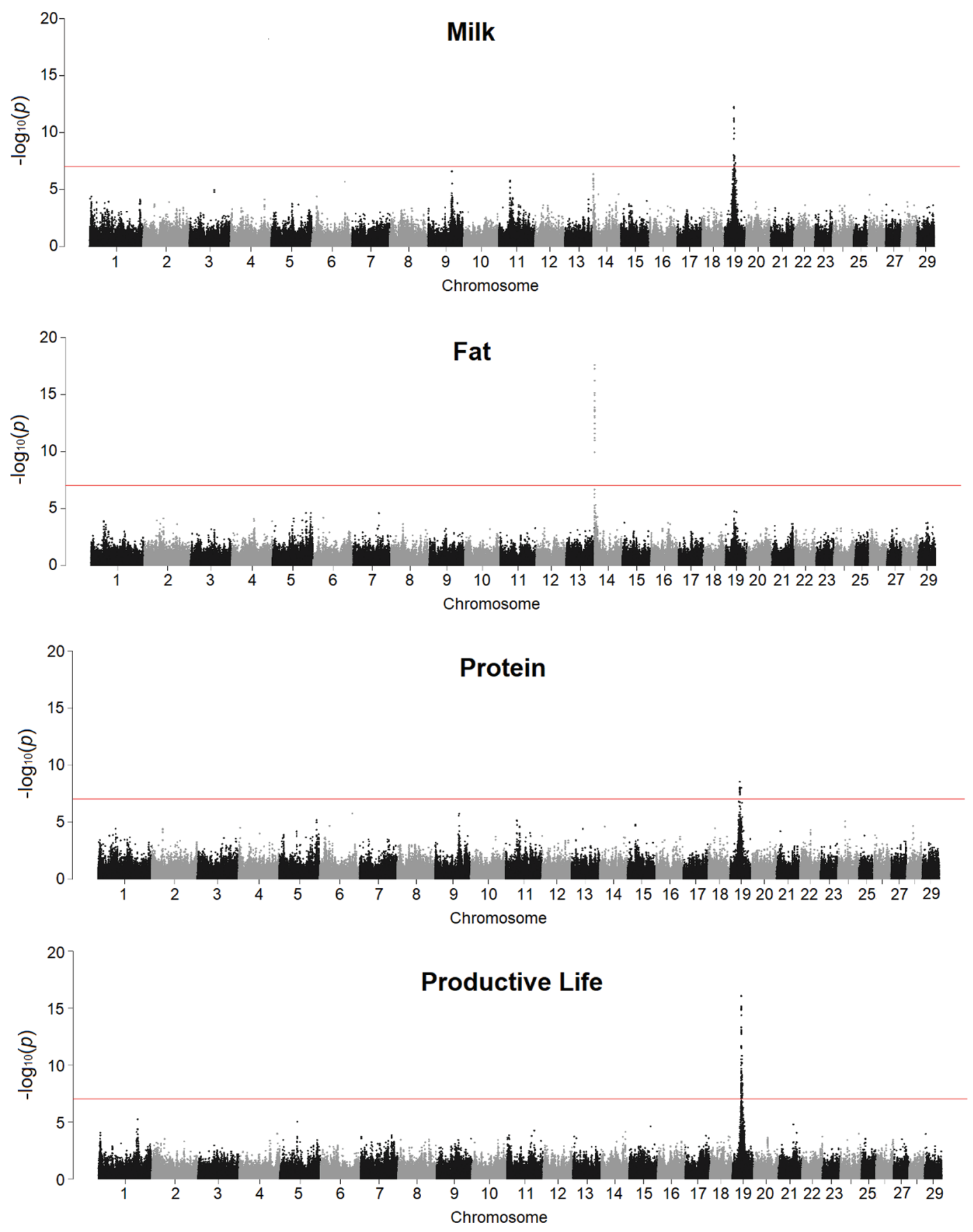

Figure 1. Manhattan plots for milk yield, fat yield, protein yield, and productive life for Guernsey cattle. The horizontal line indicates the genome-wide significance threshold. 
on health until 1994, when productive life and SCS were added to the index, and DPR was not included until 2004.

For production and conformation traits, the top SNP of the major QTL region in 26.2 to $28.3 \mathrm{Mb}$ on BTA19 are common variants (Table 3 ). The closest genes to these top SNP include MYH10, AURKB, RABEP1, PIK3R6, and WSCD1 (Table 3). Among the genes flagged, MYH10 (myosin heavy chain 10) had effects on several production traits (milk yield, protein percentage) and conformation traits (stature, rump width, dairy form, teat length) of Guernsey cattle (Table 3). The MYH10 gene is a member of the myosin superfamily of protein-coding genes in cattle, humans, mice, chickens, sheep, and several other species. The MYH1O gene is associated with skeletal muscle in human (Mascarello et al., 2016), muscle characteristics in beef cattle (Yang et al., 2019) and pigs (Óvilo et al., 2014), and body size in sheep (Kominakis et al., 2017; SignerHasler et al., 2019). In Holstein cattle, the MYH10 gene is associated with milk production (Do et al., 2017) and body conformation traits (Abo-Ismail et al., 2017; Jiang et al., 2019), which is consistent with our findings. The role of MYH10 in controlling body conformation traits is similar between Guernsey and Holstein cattle. However, in contrast with Guernsey cattle, the largest QTL in Holstein cattle influencing several conformation traits and calving traits is on BTA18 (Cole et al., 2009; Abo-Ismail et al., 2017). Another $M Y H$ gene, MYH14 (myosin heavy chain 14), is a candidate gene associated with the BTA18 QTL in Holsteins (Abo-Ismail et al., 2017). These findings indicate a general role for the MYH gene family (e.g., MYH10, MYH14) in controlling body conformation traits of dairy cattle, which could be explained by the important role of expression of the $M Y H$ gene family in mammalian muscle physiology (Weiss and Leinwand, 1996).

Chromosome 19 was selected for detailed analysis based on an examination of the allele substitution effects that are computed as part of routine genome evaluations. Those preliminary results showed a large QTL on BTA19 affecting many traits, but few QTL on other chromosomes. These data are not shown because they are proprietary information belonging to the Council on Dairy Cattle Breeding (Bowie, MD). Access to those data may be requested from João Dürr, chief executive officer of the Council on Dairy Cattle Breeding (joao. durr@uscdcb.com).

Although power calculations are not straightforward for GWAS studies (e.g., Ohashi and Tokunaga, 2001; Delongchamp et al., 2018), it is clear that the sample size available in this study limits its ability to detect QTL of moderate or small size for most traits, and even large QTL may not be detectable for traits with
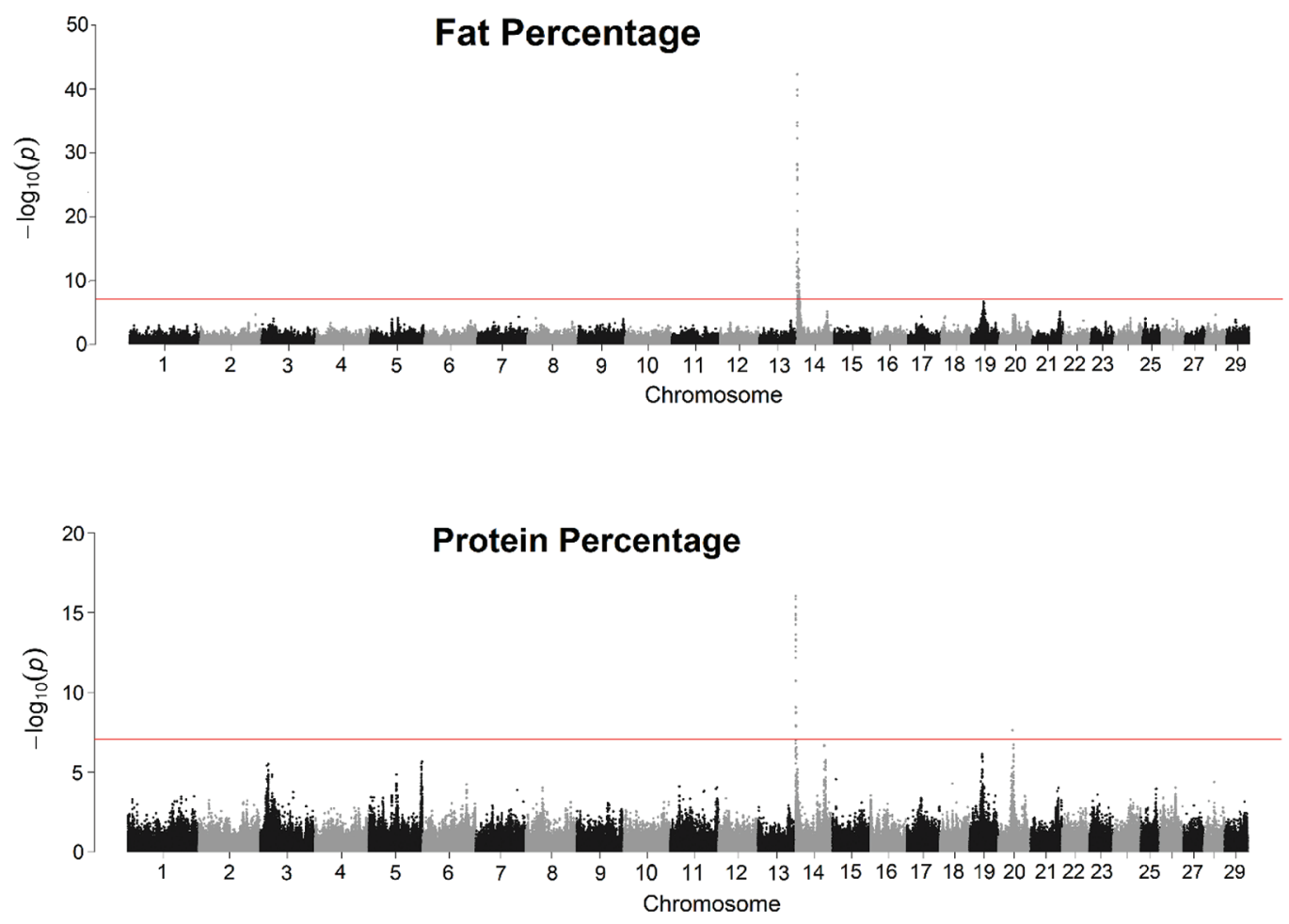

Figure 2. Manhattan plots for milk fat percentage and protein percentage for Guernsey cattle. The horizontal line indicates the genome-wide significance threshold. 

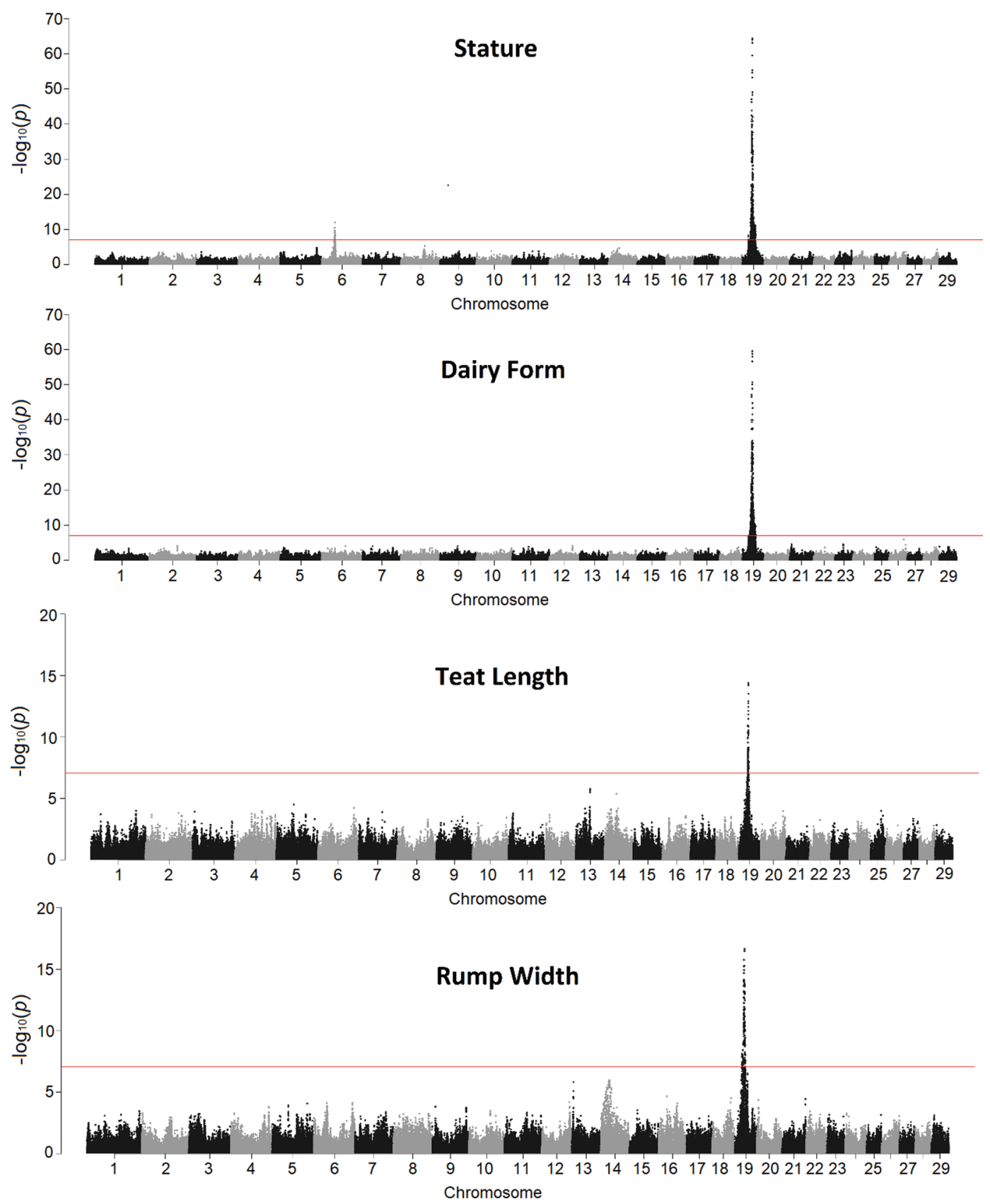

Figure 3. Manhattan plots for stature, dairy form, teat length, and rump width for Guernsey cattle. The horizontal line indicates the genome-wide significance threshold.

low heritability (e.g., fertility). Our results should be interpreted as a lower bound, in a sense, of the number of true QTL in the Guernsey population.

\section{Testing for Multiple QTL on BTA19}

For most traits, no additional genome-wide significant SNP were detected on BTA19 after fixing the most significant SNP as covariates in the model, indicating a single independent SNP associated with the related traits on BTA19 (Table 5). An example is shown in Figure 6 for teat length, where no additional significant SNP were detected after the top SNP from GWAS was fixed in the model. However, for protein, dairy form, and stature, multiple independent SNP were detected on BTA19 that are significantly associated with these traits (Table 5). The multiple, independent, significant SNP on BTA19 for these 3 traits might indicate 

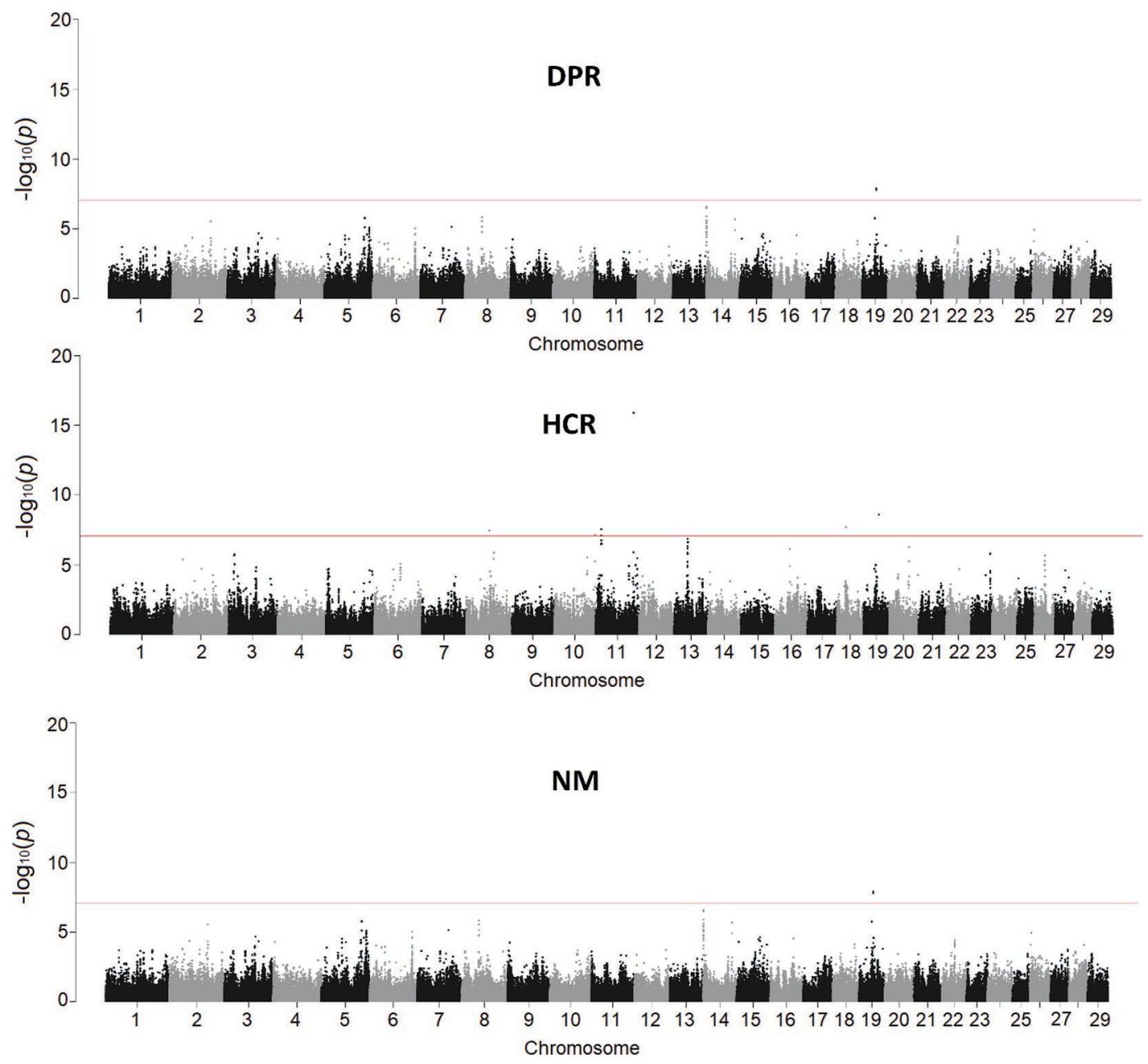

Figure 4. Manhattan plots for daughter pregnancy rate (DPR), heifer conception rate (HCR), and net merit (NM) for Guernsey cattle. The horizontal line indicates the genome-wide significance threshold.
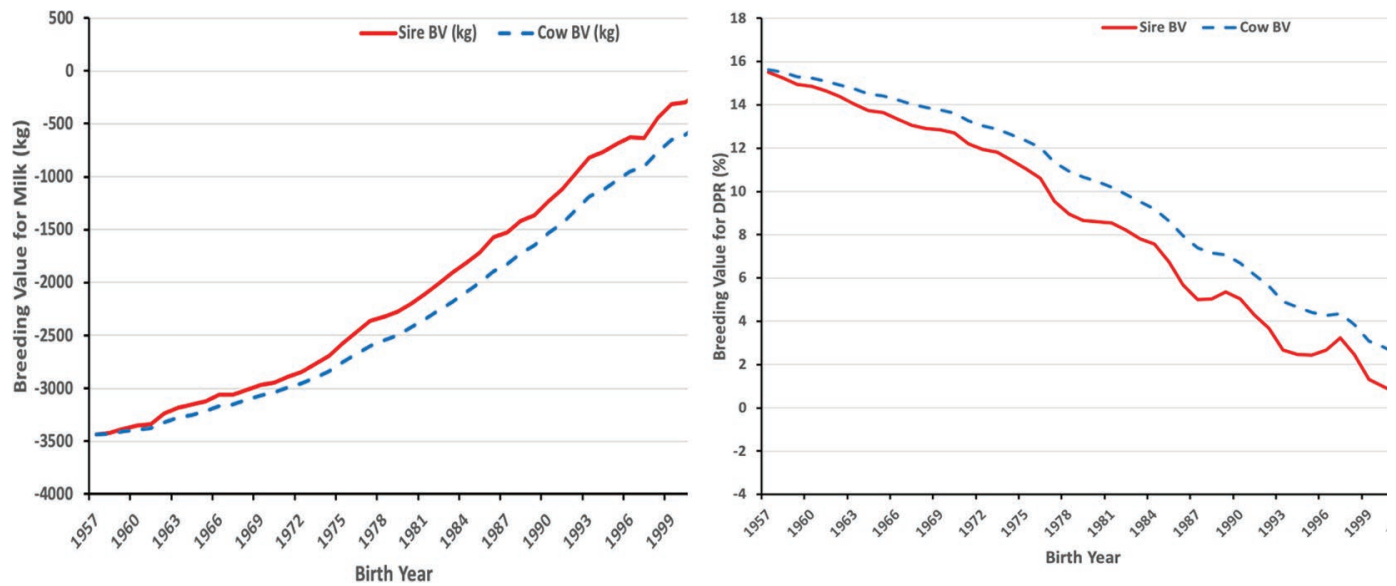

Figure 5. Genetic trend for milk yield (left) and daughter pregnancy rate (DPR, right) of Guernsey bulls (solid red line) and cows (broken blue line). BV = breeding value. Data were taken from the Council on Dairy Cattle Breeding's Genetic and Phenotypic Trend report (https:// queries.uscdcb.com/eval/summary/trend.cfm). 
Table 4. Traits included in USDA selection indices ${ }^{1}$ and the relative emphasis (\%) placed on each for the years 1971 to 2018

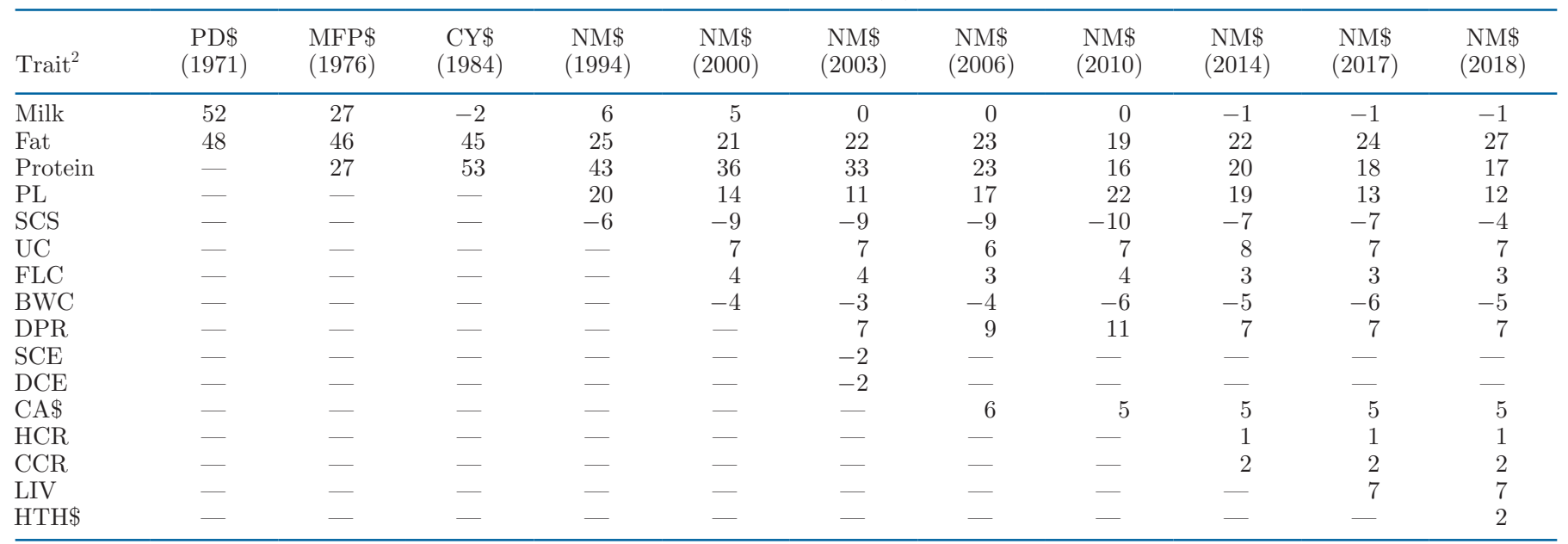

${ }^{1} \mathrm{PD} \$=$ predicted difference dollars, MFP $\$=$ milk-fat-protein dollars, $\mathrm{CY} \$=$ cheese yield dollars, and NM $\$=$ lifetime net merit.

${ }^{2} \mathrm{PL}=$ productive life $\mathrm{UC}=$ udder composite, $\mathrm{FLC}=$ foot and leg composite, $\mathrm{BWC}=$ body weight composite, $\mathrm{DPR}=$ daughter pregnancy rate, $\mathrm{SCE}=$ sire calving ease, $\mathrm{DCE}=$ daughter calving ease, $\mathrm{CA} \$=$ calving ability dollars, $\mathrm{HCR}=$ heifer conception rate, CCR = cow conception rate, $\mathrm{LIV}=$ cow livability, and $\mathrm{HTH} \$=$ health dollars.

multiple QTL associated with these traits on BTA19. Alternatively, the multiple independent SNP might indicate that these markers are partially correlated with one QTL, are in weak LD with each other, or had differences in imputation accuracy.

The marker ARS-BFGL-NGS-95155 (19:27,838,415), which has an unfavorable effect on protein yield, and the SNP BovineHD1900008426 (19:28,099,297), which has a favorable effect on milk yield, are located relatively close to one another $(260,882 \mathrm{bp})$. The measure of $\mathrm{LD}\left(\mathrm{r}^{2}\right)$ of 0.89 between them indicates fairly tight linkage, which suggests that these effects may be due to a polymorphism with pleitropic effects, rather than 2 different causative loci in the same small region. Complete pairwise LD measures computed using Haploview version 4.2 (Barrett et al., 2005) are provided in a text format in Supplemental File S1 (https://doi.org/10 .3168/jds.2020-18766).

\section{Haplotype Status of the QTL on BTA19}

The haplotype carrying the QTL on BTA19, which spans 27.1 to $28.7 \mathrm{Mbp}$, can be traced back to a US Guernsey (GUUSA000000512974, HENSLEE FARMS

Table 5. Independent SNP significantly associated with the putative QTL on BTA19 in Guernsey cattle, and direction of the SNP effect $(+=\text { positive, }-=\text { negative })^{1}$

\begin{tabular}{|c|c|c|c|c|}
\hline Trait & Position (bp) & SNP name & $\mathrm{SNP}^{2}(\mathrm{rs})$ & Direction \\
\hline Milk & $28,099,297$ & BovineHD1900008426 & rs133856141 & + \\
\hline \multirow[t]{2}{*}{ Protein } & $27,838,415$ & ARS-BFGL-NGS-95155 & rs110502730 & - \\
\hline & $31,759,563$ & ARS-BFGL-NGS-6071 & rs109214986 & - \\
\hline Productive life & $26,298,780$ & BovineHD1900008028 & rs135102299 & - \\
\hline \multirow[t]{2}{*}{ Stature } & $28,096,864$ & BovineHD1900008425 & rs137768921 & + \\
\hline & $26,692,730$ & ARS-BFGL-NGS-117046 & rs41907795 & - \\
\hline Strength & $27,838,415$ & ARS-BFGL-NGS-95155 & rs110502730 & - \\
\hline \multirow{2}{*}{ Dairy form } & $28,099,297$ & BovineHD1900008426 & rs133856141 & + \\
\hline & $36,245,752$ & BovineHD1900010701 & rs41911375 & + \\
\hline Rump angle & $28,339,070$ & BovineHD1900008517 & rs136174573 & + \\
\hline Rump width & $28,096,864$ & BovineHD1900008425 & rs137768921 & + \\
\hline Teat length & $28,099,297$ & BovineHD1900008426 & rs133856141 & + \\
\hline Udder depth & $25,859,348$ & BovineHD1900007870 & rs132856966 & + \\
\hline Net merit & $35,216,837$ & BovineHD1900010409 & rs136421332 & - \\
\hline $\mathrm{DPR}^{3}$ & $35,283,135$ & Hapmap42945-BTA-45128 & rs41643572 & - \\
\hline $\mathrm{HCR}^{4}$ & $37,705,042$ & BovineHD1900011119 & rs110141399 & + \\
\hline
\end{tabular}

${ }^{1}$ The sign is based on the effect of the minor allele and is relative to the trait definition (e.g., a positive SNP effect for stature is associated with taller cows).

${ }^{2}$ rs $=$ NCBI RefSeq ID.

${ }^{3}$ Daughter pregnancy rate.

${ }^{4}$ Heifer conception rate. 


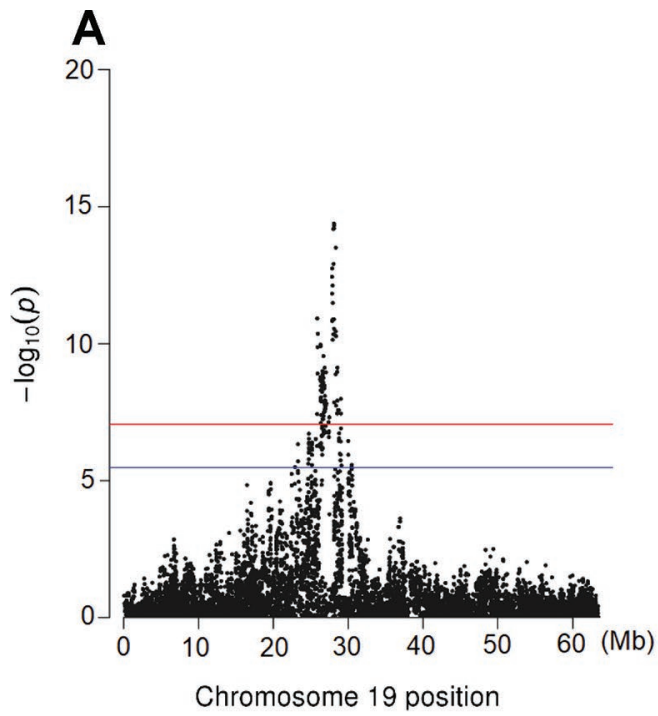

B

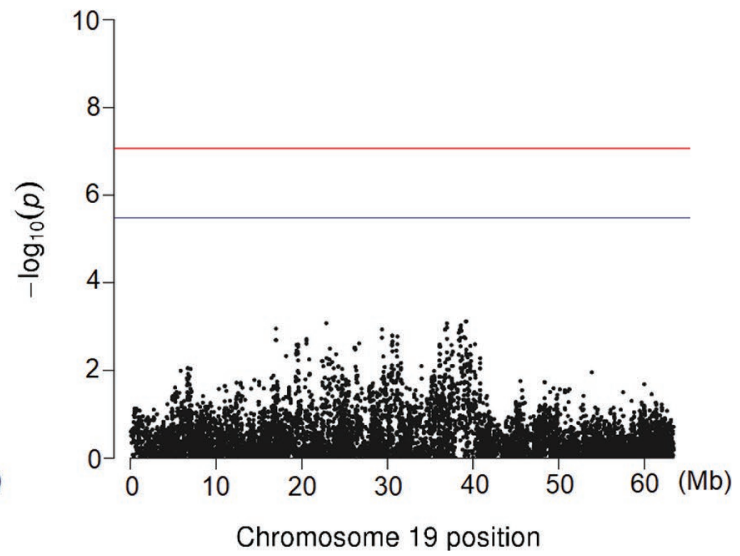

Figure 6. Conditional analyses to test for multiple QTL on BTA19 for teat length of Guernsey cattle. The $-\log (P$-value) of SNP effects on BTA19 before (A) and after (B) correcting for the most significant SNP from GWA analyses. The red and blue horizontal lines indicate the genome-wide significance threshold and chromosome-wide significance threshold, respectively.

V FAME) born in 1954. The haplotype is common at about $50 \%$ in the current population (Figure 7), and the frequencies of the haplotype indicate a potential long-term influence of this QTL on US Guernseys. This haplotype is not segregating in the genotyped Ayrshire, Brown Swiss, Holstein, or Jersey animals in the US national database.

\section{CONCLUSIONS}

A major QTL influencing milk production, body conformation, and livability of Guernsey cattle was detected on BTA19. The SNP associated with the QTL lie in the region of 26.2 to $28.3 \mathrm{Mb}$ on BTA19, which in-

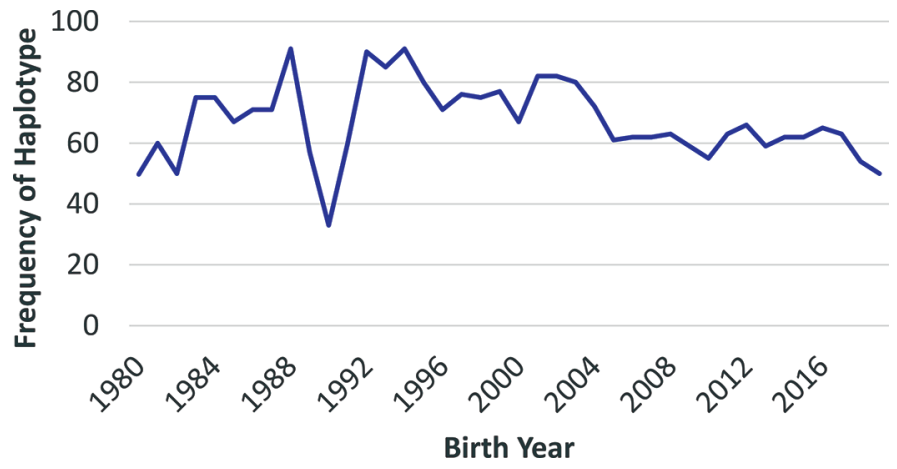

Figure 7. The frequency over time of the haplotype that contains the major QTL on BTA19 influencing milk production, conformation, and cow livability of Guernsey cattle. Due to sparsity of data from genotyped bulls born before 1980, frequencies from 1954 to 1980 were averaged into a single observation. cludes the MYH10 gene that is strongly associated with milk production and body conformation traits. For the 13 traits that showed genome-wide significance of QTL effects on BTA19, conditional analyses detected only 3 traits with additional, independent SNP with significant influence on BTA19. Those traits with multiple independent SNP were protein, dairy form, and stature of Guernsey. The haplotype carrying the QTL is common in the US Guernsey population, indicating a potential long-term influence on the breed, but was not detected in other breeds with genotypes in the US database.

\section{ACKNOWLEDGMENTS}

The Council on Dairy Cattle Breeding (CDCB; Bowie, MD) and its industry collaborators are thanked for providing phenotypic, pedigree, and genomic information used in this analysis. The Agriculture and Horticulture Development Board (Kenilworth, UK) and World Guernsey Cattle Federation (Castel, Guernsey, Channel Islands, UK) are gratefully acknowledged for providing genotypes included in this study as part of an international data exchange with CDCB. Two anonymous reviewers are thanked for their thoughtful feedback, which improved the quality of this paper. Cole, Null, and VanRaden were supported by appropriated project 8042-31000-002-00-D, "Improving Dairy Animals by Increasing Accuracy of Genomic Prediction, Evaluating New Traits, and Redefining Selection Goals." B. Li was supported in part by an appointment to the Agriculture Research Service (ARS) Research Participation Program, administered by the Oak Ridge 
Institute for Science and Education (Oak Ridge, TN) through an interagency agreement between the U.S. Department of Energy and ARS (Washington, DC). Mention of trade names or commercial products in this article is solely for the purpose of providing specific information and does not imply recommendation or endorsement by the US Department of Agriculture. The USDA is an equal opportunity provider and employer. The authors have not stated any conflicts of interest.

\section{REFERENCES}

Abo-Ismail, M. K., L. F. Brito, S. P. Miller, M. Sargolzaei, D. A. Grossi, S. S. Moore, G. Plastow, P. Stothard, S. Nayeri, and F. S. Schenkel. 2017. Genome-wide association studies and genomic prediction of breeding values for calving performance and body conformation traits in Holstein cattle. Genet. Sel. Evol. 49:82-29. https://doi.org/10.1186/s12711-017-0356-8.

Barrett, J. C., B. Fry, J. Maller, and M. J. Daly. 2005. Haploview: Analysis and visualization of LD and haplotype maps. Bioinformatics 15:263-265. https://doi.org/10.1093/bioinformatics/ bth457.

Cole, J. B., P. M. VanRaden, J. R. O'Connell, C. P. van Tassell, T. S. Sonstegard, R. D. Schnabel, J. F. Taylor, and G. R. Wiggans. 2009. Distribution and location of genetic effects for dairy traits. J. Dairy Sci. 92:2931-2946. https://doi.org/10.3168/jds.2008-1762.

Cooper, T. A., S. A. E. Eaglen, G. R. Wiggans, J. Jenko, H. J. Huson, D. R. Morrice, M. Bichard, W. G. L. Luff, and J. A. Woolliams. 2016. Genomic evaluation, breed identification, and population structure of Guernsey cattle in North America, Great Britain, and the Isle of Guernsey. J. Dairy Sci. 99:5508-5515. https://doi.org/ $10.3168 /$ jds. $2015-10445$.

Delongchamp, R., M. F. Faramawi, E. Feingold, D. Chung, and S. Abouelenein. 2018. The association between SNPs and a quantitative trait: Power calculation. Eur. J. Environ. Public Health 2. https://doi.org/10.20897/ejeph/3925.

Do, D. N., P.-L. Dudemaine, R. Li, and E. M. Ibeagha-Awemu. 2017. Co-expression network and pathway analyses reveal important modules of miRNAs regulating milk yield and component traits. Int. J. Mol. Sci. 18:1560. https://doi.org/10.3390/ijms18071560.

Garrick, D. J., J. F. Taylor, and R. L. Fernando. 2009. Deregressing estimated breeding values and weighting information for genomic regression analyses. Genet. Sel. Evol. 41:55. https://doi.org/10 .1186/1297-9686-41-55.

Jiang, J., J. B. Cole, E. Freebern, Y. Da, P. M. VanRaden, and L. Ma. 2019. Functional annotation and Bayesian fine-mapping reveals candidate genes for important agronomic traits in Holstein bulls. Commun. Biol. 2:212. https://doi.org/10.1038/s42003-019-0454-y.

Kominakis, A., A. L. Hager-Theodorides, E. Zoidis, A. Saridaki, G. Antonakos, and G. Tsiamis. 2017. Combined GWAS and 'guilt by association'-based prioritization analysis identifies functional candidate genes for body size in sheep. Genet. Sel. Evol. 49:41. https: //doi.org/10.1186/s12711-017-0316-3.

Lucy, M. C. 2001. Reproductive loss in high-producing dairy cattle: Where will it end? J. Dairy Sci. 84:1277-1293. https://doi.org/10 .3168/jds.S0022-0302(01)70158-0.

Mascarello, F., L. Toniolo, P. Cancellara, C. Reggiani, and L. Maccatrozzo. 2016. Expression and identification of 10 sarcomeric $\mathrm{MyHC}$ isoforms in human skeletal muscles of different embryological origin. Diversity and similarity in mammalian species. Ann. Anat. 207:9-20. https://doi.org/10.1016/j.aanat.2016.02.007.

Null, D. J., P. M. VanRaden, B. D. Rosen, J. R. O'Connell, and D. M. Bickhart. 2019. Using the ARS-UCD1.2 reference genome in U. S. evaluations. Interbull Bull. 55:30-34.

O'Connell, J. R. 2020. MMAP: Mixed Model Analysis for Pedigrees and Populations. Accessed Sep. 3, 2020. https://mmap.github.io/.
Ohashi, J., and K. Tokunaga. 2001. The power of genome-wide association studies of complex disease genes: Statistical limitations of indirect approaches using SNP markers. J. Hum. Genet. 46:478482. https://doi.org/10.1007/s100380170048.

Óvilo, C., R. Benítez, A. Fernández, Y. Núñez, M. Ayuso, A. I. Fernández, C. Rodríguez, B. Isabel, A. I. Rey, C. López-Bote, and L. Silió. 2014. Longissimus dorsi transcriptome analysis of purebred and crossbred Iberian pigs differing in muscle characteristics. BMC Genomics 15:413. https://doi.org/10.1186/1471-2164-15-413.

Rosen, B. D., D. M. Bickhart, R. D. Schnabel, S. Koren, C. G. Elsik, E. Tseng, T. N. Rowan, W. Y. Low, A. Zimin, C. Couldrey, R. Hall, W. Li, A. Rhie, J. Ghurye, S. D. McKay, F. Thibaud-Nissen, J. Hoffman, B. M. Murdoch, W. M. Snelling, T. G. McDaneld, J. A. Hammond, J. C. Schwartz, W. Nandolo, D. E. Hagen, C. Dreischer, S. J. Schultheiss, S. G. Schroeder, A. M. Phillippy, J. B. Cole, C. P. Van Tassell, G. Liu, T. P. L. Smith, and J. F. Medrano. 2020. De novo assembly of the cattle reference genome with singlemolecule sequencing. Gigascience 9:giaa021. https://doi.org/10 .1093 /gigascience/giaa021.

Signer-Hasler, H., A. Burren, P. Ammann, C. Drögemuller, and C. Flury. 2019. Runs of homozygosity and signatures of selection: A comparison among eight local Swiss sheep breeds. Anim. Genet. 50:512-525. https://doi.org/10.1111/age.12828.

VanRaden, P. M. 2016. Findhap.F90: Find Haplotypes and Impute Genotypes Using Multiple Chip Sets and Sequence Data. Accessed Apr. 22, 2016. https://aipl.arsusda.gov/software/findhap/.

VanRaden, P. M., D. J. Null, M. Sargolzaei, G. R. Wiggans, M. E. Tooker, J. B. Cole, T. S. Sonstegard, E. E. Connor, M. Winters, J. B. C. H. M. van Kaam, A. Valentini, B. J. Van Doormaal, M. A Faust, and G. A. Doak. 2013. Genomic imputation and evaluation using high-density Holstein genotypes. J. Dairy Sci. 96:668-678. https://doi.org/10.3168/jds.2012-5702.

VanRaden, P. M., M. E. Tooker, J. R. O'Connell, J. B. Cole, and D. M. Bickhart. 2017. Selecting sequence variants to improve genomic predictions for dairy cattle. Genet. Sel. Evol. 49:32. https://doi .org/10.1186/s12711-017-0307-4.

VanRaden, P. M., C. P. Van Tassell, G. R. Wiggans, T. S. Sonstegard, R. D. Schnabel, J. F. Taylor, and F. S. Schenkel. 2009. Invited review: Reliability of genomic predictions for North American Holstein bulls. J. Dairy Sci. 92:16-24. https://doi.org/10.3168/jds .2008-1514.

Weiss, A., and L. A. Leinwand. 1996. The mammalian myosin heavy chain gene family. Annu. Rev. Cell Dev. Biol. 12:417-439. https:// doi.org/10.1146/annurev.cellbio.12.1.417.

Wiggans, G. R., J. B. Cole, S. M. Hubbard, and T. S. Sonstegard. 2017. Genomic selection in dairy cattle: The USDA experience. Annu. Rev. Anim. Biosci. 5:309-327. https://doi.org/10.1146/ annurev-animal-021815-111422.

Wiggans, G. R., P. M. VanRaden, L. R. Bacheller, M. E. Tooker, J. L. Hutchison, T. A. Cooper, and T. S. Sonstegard. 2010. Selection and management of DNA markers for use in genomic evaluation. J. Dairy Sci. 93:2287-2292. https://doi.org/10.3168/jds.2009-2773.

Wiggans, G. R., P. M. VanRaden, D. J. Null, and J. B. Cole. 2019. Genomic predictions using more markers and gene tests. J. Dairy Sci. 102(Suppl. 1):397 (Abstr.)

World Guernsey Cattle Ferderation. 2004. Guernsey Breed History. Accessed Jan. 17, 2020. https://www.worldguernseys.com/history -of-the-guernsey.

Yang, Z., X. Zhao, X. Xiong, L. Bao, K. Pan, S. Zhou, L. Wen, L. $\mathrm{Xu}$, and M. Qu. 2019. Uncovering the mechanism whereby dietary nicotinic acid increases the intramuscular fat content in finishing steers by RNA sequencing analysis. Anim. Prod. Sci. 59:16201630. https://doi.org/10.1071/AN18205.

\section{ORCIDS}

P. M. VanRaden @ https://orcid.org/0000-0002-9123-7278

J. B. Cole 우 https://orcid.org/0000-0003-1242-4401 